\title{
A REPRESENTAÇÃO DE IDENTIDADES DE GÊNERO E DE DIVERSIDADE SEXUAL NA PRODUÇÃO LITERÁRIA PARA JOVENS LEITORES
}

Flávio Pereira Camargo Aurílio Soares da Silva

Resumo: Neste artigo, temos como objetivo fazer uma análise sobre os processos de representação de identidades de gênero, dando ênfase especialmente à diversidade sexual, particularmente na produção literária para jovens leitores. Para tanto, delimitamos como corpus de análise os livros infanto-juvenis $O$ gato que gostava de cenouras, de Rubem Alves, e $O$ menino que brincava de ser, de Georgina da Costa Martins.

Palavras-chave: literatura infanto-juvenil, currículo, identidades, homofobia.

Abstract: In this article, we aim to analyze the processes of representation of gender identities, emphasizing especially sexual diversity, particularly in literature for young readers. To do so, delimit the corpus of analysis the children's books $O$ gato que gostava de cenouras, by Rubem Alves, and $O$ menino que brincava de ser, by Georgina Martins da Costa.

Keywords: children's literature, curriculum, identities, homophobia.

\section{CONSIDERAÇÕES INICIAIS}

Atualmente, observamos uma demanda crescente nas pesquisas e nas abordagens que tendem a re/tratar de forma mais crítica a questão sobre a sexualidade de modo a enfatizar as diversidades existentes em nossa sociedade. Mas,

$\mathrm{Na}$ verdade, desde os anos sessenta, o debate sobre as identidades e as práticas sexuais e de gênero vem se tornando cada vez mais acaloradas, especialmente 
provocado pelo movimento feminista, pelos movimentos de gays e de lésbicas e sustentado, também, por todos aqueles e aquelas que se sentem ameaçados por essas manifestações. (LOURO, 2010b, p. 9-10)

Tais discussões e debates sobre sexo, gênero e sexualidade buscam não somente compreender seus mecanismos de atuação, mas, também, formular críticas aos processos de representações que atuam em uma lógica tendenciosa de supremacia das identidades tradicionais em detrimento das diversidades, tidas como "inferiores".

Todo esse alvoroço se deve, em sua maioria, à reivindicação dos direitos por aqueles que, há muito tempo, vêm sendo postos às margens da sociedade por uma identidade que se quer "superior" às demais. Esses movimentos passam a questionar:

toda uma noção de cultura, ciência, arte, ética, estética, e educação que, associada a esta identidade, vem usufruindo, ao longo dos tempos, de um modo praticamente inabalável, a posição privilegiada em torno da qual tudo mais gravita. (LOURO, 2010a, p. 42)

Sem dúvida, a partir da segunda metade do século $X X$, temos um recrudescimento nas reflexões e teorizações sobre as questões das mulheres, dos negros, dos homossexuais, entre outros grupos que vêm sendo 
ignorados e silenciados por aqueles mencionados por Rick Santos (1997), como, por exemplo, os homens cristãos, brancos e heterossexuais $-\mathrm{CBH}$.

Partindo desses pressupostos, temos como objetivo, neste trabalho, fazer uma análise sobre os processos de representação de identidades de gênero, dando ênfase especialmente à diversidade sexual, particularmente na produção literária para jovens leitores. Para alcançar nossos objetivos, delimitamos como corpus de análise os livros infanto-juvenis $O$ gato que gostava de cenouras, de Rubem Alves (2009), e O menino que brincava de ser, de Georgina da Costa Martins (2000).

Esses livros nos chamam a atenção pela maneira como retratam, de forma crítica, um momento novo na vida de jovens que estão entrando em um período de descobrimento de sua personalidade, de sua(s) identidade(s), e de sua sexualidade. Além disso, explicitam como essas revelações e mudanças pelas quais a criança passa, muitas vezes, se dão de forma angustiante, conflituosas e, em alguns casos, traumáticas.

Dito isso, este trabalho se justifica justamente em decorrência de uma necessidade de analisarmos, na literatura infanto-juvenil brasileira produzida nas últimas 
décadas, como ocorrem essas representações de gênero, de identidade e de diversidade sexual, e como essas obras podem contribuir para o rompimento com alguns preconceitos arcaicos e enraizados em nossa sociedade.

\title{
1. A REPRESENTAÇÃO DE IDENTIDADES DE GÊNERO E DE DIVERSIDADE SEXUAL NO DISCURSO LITERÁRIO
}

\begin{abstract}
A identidade é um significado - cultural e socialmente atribuído. A teoria cultural recente expressa essa mesma ideia por meio do conceito de representação. Para a teoria cultural contemporânea, a identidade e a diferença estão estreitamente associadas a sistemas de representação. (SILVA, 2007, p. 89)
\end{abstract}

Não é difícil perceber que as identidades estão intrinsecamente ligadas aos processos de representações, como veremos adiante. Mas o conceito de representação que encerra, tanto a linguagem, quanto outros sistemas de significações, como aponta Tadeu Silva (2007), tem sido questionado pelos pós-estruturalistas. Porém,

isso não impediu, entretanto, que teóricos e teóricas ligados sobretudo aos Estudos Culturais, por exemplo, Stuart Hall, 'recuperassem" o conceito de representação, desenvolvendo-o em conexão com uma teorização sobre a identidade e a diferença. (SILVA, 2007, p. 90 , grifo do autor) 
Para Hall, "a representação atua simbolicamente para classificar o mundo e nossas relações no seu interior" (1997, nos termos de WOODWARD, 2007, p. 8). Mas qual o vínculo da representação com os processos de determinações das identidades? Primeiramente, precisamos saber o que se entende por identidade.

Um pensamento quase consensual é de que a identidade está intimamente ligada à diferença em um processo de dependência exclusiva (exclusiva no sentido de excluir), ou seja, a afirmação de uma identidade implica na ausência de outras, a saber, as diferenças; mas a existência dessas "outras" identidades é fundamental para a subsistência daquela.

Tadeu Silva (2007) argumenta que é comum afirmar a identidade como aquilo que se é: "sou brasileiro", "sou negro", "sou heterossexual", "sou jovem", "sou homem". Nesta perspectiva, diz Silva, "ela é auto-contida e autosufuciente", ou seja, refere-se a si mesma como algo positivo. Assim como a identidade, a diferença também é comumente concebida nessa mesma linha de raciocínio, como entidade independente e, nesse caso, em oposição à identidade, ou seja, ela é aquilo que o outro é: "ela é italiana", "ela é branca", "ela é homossexual", "ela é velha", "ela é mulher" (SILVA, 2007, p. 74, grifos do autor). 
No entanto, Silva mostra que essa noção ou concepção de positivo/negatividade de identidade e diferença é apenas uma forma resumida de representá-las. Assim, concebendo-as (identidade e diferença) como meras criações da língua, esta se encarrega de simplificar a maneira como aquelas são representadas.

Outro autor que compartilha dessa mesma ideia de identidade marcada pela diferença é Kathryn Woodward. Para ela, "a identidade é relacional". Ou seja,

depende, para existir, de algo fora dela: a saber, de outra identidade [...], de uma identidade que ela não é", diferente, "mas que, entretanto, fornece as condições para que ela exista. A identidade é, assim, marcada pela diferença. (WOODWARD, 2007, p. 9)

Aqui poderíamos questionar o seguinte: se a identidade é concebida não por aquilo que se é, mas, sim, por aquilo que não se é, ou seja, pelo que o outro é, como se dá o processo de determinação da identidade, principalmente das identidades hegemônicas e suas relações de soberanias?

É exatamente aí que entra o papel dos processos de representações. Eles se dão a partir de uma tendência de fixação da identidade. Segundo Woodward (2007), a representação abrange, em suas relações, sistemas 
simbólicos que produzem os significados nos quais os sujeitos estão posicionados. Para a autora, tanto aquilo que somos, quanto nossas experiências são frutos dos significados produzidos pelas representações.

A representação, compreendida como um processo cultural, estabelece identidades individuais e coletivas e os sistemas simbólicos nos quais ela se baseia fornecem possíveis respostas às questões: Quem eu sou? O que eu poderia ser? Quem eu quero ser? (WOODWARD, 2007, p. 17)

Tadeu Silva compreende o conceito de representação na perspectiva dos teóricos e estudiosos pós-estruturalistas, que abrange uma carga de ambiguidade, instabilidade e indeterminação. Portanto, o referido conceito é compreendido como um sistema linguístico e cultural que não se aplica a um suposto referente, mas, em vez disso, é apenas uma forma de atribuição de sentido que está vinculado a relações de poder.

\section{A PRODUÇÃO LITERÁRIA PARA JOVENS LEITORES}

Acabamos reagindo com mais intensidade à tristeza literária do que à miséria perto de nós. (STEINER, 1988, p. 23)

Nesse cenário de liquidez que aponta o filósofo Bauman, cabe perguntar de que modo a literatura infantil e juvenil 
se constrói como objeto artístico, mas também qual a sua função, o seu papel na formação de crianças e jovens. (TURCHI, 2008, p. 213)

Muito se tem argumentado sobre o caráter polifônico dos textos literários, mas pouco se tem proposto determinar a utilidade e a função desse recurso na formação de um senso crítico capaz de estabelecer dimensões que vão além de uma interpretação monótona e trivial dos textos literários. Graça Paulino (2005) considera uma "falta de ética" textos ficcionais destinados às crianças com um procedimento monológico. Assim,

traindo a abertura para outras vozes, a polifonia assumida, própria da enunciação literária, diversos autores se tornam tutores, e querem ensinar, mostrando um caminho certo aos pequenos que leem seus textos. (PAULINO, 2005, p. 15)

Nos livros infanto-juvenis O gato que gostava de cenoura e $O$ menino que brincava de ser, observamos um enredo que explicita ao leitor temas considerados tabus, sobretudo no que diz respeito à diferença. A problemática levantada nesses livros deixa bem clara a intenção de seus autores em abordar assuntos que tocam de modo sensível e acurado no senso crítico dos leitores aos quais são direcionados. Isso se explica tanto pelas implicaturas expostas pelo enredo, como 
pelas estratégias narrativas e discursivas que seduzem o leitor no ato da leitura, solapando dele os seus preconceitos.

No entanto, Graça Paulino argumenta que "mais que um padrão de certo e errado na leitura literária, há um padrão ético nela incluído" (2005, p. 19). E esse padrão ético deve proceder de ambas as partes, não somente do escritor, mas também do leitor, pois:

a leitura literária eticamente desejável tem um campo de liberdade e de subjetividade digno de atenção". Para essa autora, "ler a literatura como ética literária é, pois, seguir a proposta estética sem ignorá-la ou traí-la. (PAULINO, 2005, p. 19-20)

Na realidade, o jovem, ao se colocar na condição de leitor, busca não somente absorver conhecimentos "pré-prontos" e/ou muitas vezes triviais, como se tem visto por aí. Mas, muito mais, pois ele espera encontrar informações das quais ele possa se colocar como debatedor e como ser capaz de se posicionar diante dos questionamentos veiculados no âmbito social.

É nessa direção polifônica, subjetiva, ética e crítica que a literatura encontra seu fundamento, onde "o outro está presente, portanto, de forma assumida no discurso literário, e mais presente nele que em outros discursos" (PAULINO, 
2005, p. 14). E a produção literária infanto-juvenil está se colocando como precursora dessa mobilização.

Não raro ouvimos questões em que se põe em questionamento a eficácia da literatura na construção de uma mentalidade humana, no que diz respeito ao seu caráter humanizador e crítico ao objetivar uma sociedade melhor e mais acolhedora. Esse questionamento está atrelado à barbárie humana, em destaque, àquelas iniciadas na Europa, em sociedades tidas como o berço da civilização, como enfatiza Steiner (1988).

Tais questionamentos estão vinculados, em sua maioria, a uma concepção que valoriza a capacidade científica e seu poderio revolucionário, colocando, em contrapartida, a literatura. Mas, como reitera Steiner (1988), não duvidamos, em hipótese alguma, das contribuições da ciência em nossas vidas, mas, nos cabe questionar a difamação literária que contribui para as questões em que a própria ciência é falha.

Com isso quero dizer que acrescentaram pouco a nosso conhecimento ou controle das possibilidades humanas, que comprovadamente existe mais compreensão da questão do homem em Homero, Shakespeare ou Dostoievski do que em toda neurologia ou a estatística. (STEINER, 1988, p. 24) 
Não estamos negando que há certo despropósito literário nas últimas décadas, desviando, “assim, o que seria próprio da literatura enquanto arte, como revela sua própria e longa história: o desdobramento partilhado do imaginário por meio da linguagem" (PAULINO, 2005, p.14), mas afirmando que:

[a] ciência pode ter dado instrumentos e insanos pretextos de racionalidade àqueles que planejam assassínios em massa. Pouco ou nada nos diz sobre suas motivações, um assunto sobre o qual vale a pena ouvir Ésquilo ou Dante. Tampouco, a julgar pelas ingênuas declarações políticas proferidas por nossos atuais alquimistas, pode fazer algo notável para tornar o futuro menos vulnerável ao inumano. A luz que temos sobre nossa condição essencial e íntima ainda é concentrada pelo poeta. (STEINER, 1988, p. 25)

Todas essas observações têm como propósito em si comprovar que a produção literária é uma necessidade, principalmente no que venha servir de subsídio aos/às cidadãos(ãs) em seus processos de formação. Mas, como isso deve acontecer? Vejamos algumas proposições em nossas análises.

\subsection{LEITURA E ANÁLISE DO CORPUS LITERÁRIO}

Acreditamos que a literatura precisa fazer parte, ainda mais, da vida dos jovens. Mas, para isso, é necessária 
uma distinção entre a literatura construtiva, que tem um compromisso com o social, e aquela com intuito apenas comercial. Esta última é despropositada e desprovida de toda lógica enunciativa social.

É como se alguns escrevessem por falta de algo mais interessante - quem sabe lucrativo? - a fazer, embora não saibam em que universo estão, embora tenha lido pouco e mal, embora se revelem presunçosos apenas. (PAULINO, 2007, p. 16)

Por esse e outros motivos, apresentamos, aqui, como forma de literatura que mais se direciona a esse ideal, os livros já mencionados, $O$ gato que gostava de cenoura e $O$ menino que brincava de ser. Estes livros se destacam por provocar uma reflexão no jovem leitor e, não muito distante, suscitar nele uma introspecção acerca de assuntos considerados tabus. Eles vêm reforçar todos esses questionamentos que se fazem acerca das representações de identidades de gênero e de sexualidades. Apesar de suas histórias serem voltadas para um público, às vezes, ainda desprovido de todo esse conhecimento que engloba a problemática enfatizada acima, esses livros trazem, de maneira sutil e profundamente tocante, informações imprescindíveis acerca das identidades e da diferença que as constitui.

Observamos que, em ambos os livros, o enredo gira em torno de um personagem com uma identidade marcada 
pela diferença. Gulliver, em O gato que gostava de cenoura, é um gato que não gosta de comer aquilo que normalmente eles comem (peixes, pássaros, ratos). Em vez disso, ele come cenouras, algo totalmente repudiado pelos indivíduos de sua espécie. Já Dudu, em $O$ Menino que brincava de ser, é um garoto que gosta das personagens femininas (bruxas, fadas, princesas) e se veste de mulher - ao brincar de ser para representá-las. Portanto, os autores destas narrativas desenvolvem suas histórias dentro de um padrão que se sustenta atualmente na sociedade e na própria família: a não aceitação das diferenças, pois Gulliver e Dudu são vítimas do preconceito social e familiar. Mas, por que e como isso acontece ainda nos dias de hoje, principalmente dentro da família?

A criança, antes mesmo de nascer, é condicionada a certas situações pela sociedade em geral. Por exemplo, sua sexualidade, que é determinada antes do parto, leva em conta apenas seu sexo condicionando-o ao gênero correspondente. Isso se dá por uma lógica que tende a reproduzir "a ordem compulsória" de obrigatoriedade entre "sexo, gênero e desejo" (BUTLER, 2008, p. 24). Dentre essa condicional, estão várias outras exigências tanto sociais quanto familiares. No entanto, quando uma delas é desviada 
do "normal" defendido por essa ordem, surge o "outro", considerado como o "anormal", o "excêntrico", tornando-se o princípio de toda essa cadeia de repulsão e exclusão.

Quando essa "anormalidade" ocorre, observamos certo padrão sequencial de atitudes que são mostradas nos livros, que se iniciam na família e se expandem para além dela, conforme verificamos abaixo.

1 - Ao saber da diferença de seus filhos, os pais agem de forma desesperada, como se algo de muito grave estivesse ocorrendo: "Seu pai quase morreu do coração [...]. E ali, ele e a gata, sua mulher, choraram amargamente" (ALVES, 2012, p. 8) e "No começo, a mãe de Dudu ficou muito preocupada [...]. A mãe dessa vez achou que era demais" (MARTINS, 2000, p. 6-8).

A sociedade atual é regida dentro do padrão de normalidade dohomem, branco,cristão, heterossexual,comojámencionamos acima, e, paralelo a essas identidades, existe uma cadeia quase infindável de outras identidades de maior destaque que se autodenominam superiores. Diante disso, há uma imposição por parte dos pais em relação aos filhos deverem herdar suas identidades. E quando essa regra é quebrada, há uma subversão da ordem "normal", pois o filho passa a pertencer a outro grupo social desconhecido e ignorado pelos pais. 
2 - Os pais tendem a buscar um culpado para o que está acontecendo com o filho. Vejamos: "- Tudo culpa dessa professora que fica incentivando essas coisas - pensava ela [a mãe de Dudu]" (MARTINS, 2000, p. 8).

Quando a ordem do pai é subvertida, intuitivamente é deduzido que o filho está sobre a influência de outra ordem, que tende a tirá-lo do caminho "certo". Isso se dá no mesmo sentido em que Rick Santos fala sobre o "mito da conversão" - se essa diferença for considerada sexual - referindo-se ao pensamento de que todos os homossexuais tendem a converter jovens a seus modos de vida. Além disso, os pais acreditam no mito do "heterocentrismo", que "é a crença de que todos os alunos e o mundo em geral são heterossexuais" (SANTOS, 1997, p. 183-184).

3 - Há uma busca por ajuda médica/psicológica pelos pais, por acreditarem que essa diferença constitutiva da identidade de seus filhos se trata de uma doença: "Seus pais não desanimaram. Tinha de haver uma cura. Enviaram Gulliver a um psicanalista" (ALVES, 2012, p. 12) e "Vamos levá-lo no doutor Endocrinologista. É ele quem sabe tratar dessas doenças" (MARTINS, 2000, p. 56).

Atualmente não é raro observarmos esse tipo de preconceito principalmente com relação aos homossexuais. 
No entanto, essa atitude de taxar as pessoas como doentes, loucas e pecaminosas por pertencerem a um modo de vida diferente do padrão considerado como "normal" já foi mais contundente, como enfatiza Louro, ao falar sobre os desafios da educação atual diante das diferenças dos outros, pois não podemos mais simplesmente "encaminhá-los" aos especialistas para orientá-los. “Mas certamente é impossível continuar ignorando-os" (LOURO, 2010a, p. 49-50).

4 - Há uma acentuada discriminação familiar e/ou social: "Gulliver tornou-se objeto de zombaria. Passaram a chamálo de coelho" (ALVES, 2012, p. 10) e "- Mulherzinha! Gritou o pai" (MARTINS, 2000, p. 38).

Didier Eribon, ao discutir o conceito de injúria e ao relacioná-lo à questão gay, mostra que essas agressões verbais causam traumatismos psicológicos por toda a vida:

Aquele que lança a injúria me faz saber que tem domínio sobre mim, que estou em poder dele. E esse poder é primeiramente o de me ferir. De marcar a minha consciência com essa ferida ao inscrever a vergonha no mais fundo da minha mente. (2008, p. 28)

A injúria em relação à identidade do outro, o diferente, é marcada por meio de atos de linguagem que têm como objetivo delimitar e demarcar os territórios entre as 
diferentes identidades. É por meio da linguagem que nomeamos o outro, que lhe atribuímos uma identidade, seja ela estigmatizada ou não.

Nesse caso, os marcadores linguísticos "coelho" e "mulherzinha" explicitam a diferença e fazem dela alvo de zombaria, fruto do preconceito e da discriminação. Um leitmotiv a partir do qual aquele que está no centro se sente no direito de excluir e marginalizar o outro, apontando e explicitando em sua identidade o que é diferente do padrão preestabelecido. A diferença pode se referir, nesse caso, tanto a um hábito alimentar (Gulliver), quanto a uma performance feminina (Dudu), que solapam os pilares de uma heterossexualidade compulsória, pois o gosto alimentar de Gulliver, como o leitor irá perceber no desenrolar da narrativa, é, na verdade, uma metáfora, de sua identidade de gênero e sexual.

5 - A discriminação faz a vítima retrair-se socialmente e encontrar nas amizades um elo de confiança e compreensão: “De repente, Gulliver compreendeu que o professor sabia tudo sobre ele. Sabia e compreendia. Compreendia e não queria consertá-lo, não queria torná-lo igual aos outros. Ele era amigo" (ALVES, 2012, p. 18) e "A outra avó era muito legal, Dudu gostava muito dela" (MARTINS, 2000, p. 44). 
O preconceito solapa do ser humano a sua liberdade, a sua vivência em sociedade. O indivíduo discriminado se sente não pertencendo ao meio social em que vive. Para Eribon, a injúria como ato linguístico é performativo, ou seja, atua como um efeito separador entre os "normais" e os "estigmatizados", "fazendo esse corte entrar na cabeça dos indivíduos. A injúria me diz o que sou na medida em que me faz ser o que sou" (ERIBON, 2008 p. 29). É a partir dessa reclusão que a vítima do preconceito e da discriminação busca encontrar nas amizades um vínculo confiável e acolhedor. "Assim, o modo de vida homossexual está fundado nos círculos concêntricos das amizades ou na tentativa sempre recomeçada de criar tais redes e de estabelecer tais amizades" (ERIBON, 2008, p. 39).

Acreditamos que os cinco tópicos citados acima explicitam uma dimensão abrangente acerca da identidade e da diferença em nosso corpus literário. Observamos que a intenção do(s) autor(s) é clara e objetiva: propiciar ao jovem leitor condições necessárias para avaliar, a partir de suas perspectivas elucidativas, a posição do outro e a sua subjetividade que são questionadas, justamente por serem diferentes. Ou seja, além do recurso polifônico, há uma questão "polissêmica" subjetiva inserida nos textos, que 
é valorizada pelos autores. Essa polissemia direcionada ao leitor é a responsável por criar um campo aberto para a discussão ética e estética do texto literário ao tratar da representação dessas identidades de gênero e sexuais na formação de jovens leitores.

A partir dos questionamentos colocados por nós, ousamos afirmar que, se as identidades consideradas "excêntricas" não estão sendo devidamente representadas, ou estão sendo representadas de modo estereotipado, uma forma eficaz de problematizar essa representação se dá através da diversidade de vozes presentes no texto literário, onde a voz do outro tem uma sonoridade e uma abrangência de igualdade com as demais, onde se possa questionar, não por petulância, mas por ousadia, "sobre o poder da representação e sobre como e por que alguns significados são preferidos relativamente a outros" (WOODWARD, 2007, p. 18).

É dentro desse contexto de questionamentos que colocamos em discussão uma das formas de discriminação mais evidentes atualmente: a homofobia. A discriminação sexual se realiza dentro de uma diversidade crescente de identidades que vem conquistando gradativamente seu espaço em nossa sociedade, se levarmos em conta toda a sua história de lutas pela igualdade de direitos civis e por sua visibilidade. No entanto, 
a visibilidade gay, hoje, não significa que um certo número de pessoas teriam decidido ao longo dos últimos anos definir-se pela sexualidade, mas que um número cada vez mais importante de indivíduos gays cessou de dissimular a parte "noturna" de sua vida. Não foi porque os gays teriam de repente decidido deixar suas identidades sociais até ali bem homogêneas e sem falhas para aderir unicamente à identidade sexual; foi porque um grande número deles cessou de esconder essa identidade sexual que os define tanto quanto a identidade profissional que surgiu à luz do dia esse "mundo gay", do qual participavam de maneira mais ou menos clandestina. (ERIBON, 2008, p. 41-42)

Todavia, não queremos provar que há uma fórmula mágica - até porque não há - que possa pôr fim, de uma hora para outra, a todo esse panorama de discriminação que está arraigado em nossa cultura por sistemas poderosos de representação. Mas mostrar o caminho que consideramos mais conveniente para se chegar a um mundo onde todos possam, realmente, compartilhar do meio social sem precisar esconder aquilo que põe em evidência as suas subjetividades.

Acreditamos que o passo inicial em uma direção possível está no sistema de ensino. A escola, como um dos principais veículos de disseminação de saberes e de valores de um 
sujeito, pode colocar em discussão temas relativos à diversidade sexual.

Para que o currículo reflita toda a humanidade é necessário que este inclua questões de gênero, classe, raça, e sexualidade, desta forma criando um espaço para todas as vozes, passando então a realmente refletir as características de toda a população". (SANTOS, 1997, p. 182-183)

Justamente,

por isso, é importante ver o currículo não apenas como sendo constituído de "fazer coisas" mas também vê-lo como "fazendo coisas às pessoas". O currículo é aquilo que nós, professores/ as e estudantes, fazemos com as coisas, mas é também aquilo que as coisas que fazemos fazem a nós. O currículo tem de ser visto em suas ações (aquilo que fazemos) e em seus efeitos (o que ele nós faz). Nós fazemos o currículo e o currículo nos faz. (SILVA, 2009, p. 194, grifos do autor)

Dessa maneira, o currículo se torna uma forma de conscientização ou de disciplinamento social das diferenças, pois "de uma maneira global, pode-se dizer que as disciplinas são técnicas para assegurar a ordenação das multiplicidades humanas" (FOUCAUT, 2009, p. 206). 


\section{CONSIDERAÇÕES FINAIS}

Rick Santos, ao discutir sobre o tabu da denominada literatura gay e lésbica no currículo, afirma que "a barreira mais forte contra o ensino de literatura gay e lésbica é a homofobia, ou seja, o medo irracional de homossexuais" (SANTOS, 1997, p. 183). E faz o seguinte questionamento:

Pessoalmente, como educador e ser humano, muitas vezes me perguntei o que exatamente na homossexualidade parece assustar tanto alguns heterossexuais. Os gays e lésbicas não têm a intenção de dominar a sociedade. Como um grupo, eles estão simplesmente lutando pelo direito de serem incluídos nela com os mesmos (nem melhores, nem piores) privilégios e responsabilidades. (1997, p. 187)

Esse é um tipo de posicionamento que merece uma reflexão mais aprofundada. E isso nos obriga a buscar respaldo na história. Guacira Lopes Louro argumenta que "a homossexualidade e o sujeito homossexual são invenções do século XIX" (LOURO, 2008, p. 29). Antes disso, afirma a autora, esse tipo de sexualidade era considerado como sodomia: era indesejável, pecaminosa e contagiosa. Mas, em meados desse século, "a prática passava a definir um tipo especial de sujeito que viria a ser assim marcado e reconhecido" (LOURO, 2008, p. 29). 
A partir daí, podemos concluir que a homofobia tem uma tradição cultural histórica e que sua origem parece estar atrelada a questões religiosas. Mas, mesmo assim, poderíamos questionar como e de que forma isso se dá, atualmente, em uma sociedade que se aparenta tão desvencilhada dos velhos costumes e aberta a tantas inovações em diversos campos do saber.

Além da homofobia, que se refere ao medo irracional de homossexuais, Rick Santos fala sobre outros dois fatores - já mencionados acima -, que também contribuem para o recrudescimento desse preconceito, além de serem responsáveis por manter o assunto fora do currículo. São eles: o heterocentrismo, que é o pensamento de que todas as pessoas são heterossexuais, e o mito da conversão, ideia falsa de que

todos os homossexuais são criaturas solitárias e predadoras como um vampiro, cuja única meta de vida é "converter" jovens ao seu tipo de vida marginal de promiscuidade e pecado. (SANTOS, 1997, p. 184 , grifo do autor)

Percebemos, portanto, que não somente a homofobia, mas também o heterocentrismo e o mito da conversão, juntos, são atualmente os principais argumentos e propulsores que mantêm viva toda essa cadeia de difamação, discriminação e exclusão das pessoas homossexuais. 
Assim, a literatura que trata de questões referentes à diferença no currículo é uma questão de inclusão, ou seja, é uma forma de dar ao "outro" a condição de igualdade no campo da representação, pois,

pode-se dizer mesmo que é através do processo de representação que o currículo se vincula com a produção de identidades sociais. É no currículo que o nexo entre representação e poder se realiza, se efetiva. (SILVA, 2009, p. 200)

Mas é preciso, como alerta Rick Santos, que fiquemos atentos para a possibilidade de manifestação homoerótica ou homoafetiva nos textos literários, para que não passemos despercebido por elas, deixando-as em segundo plano.

A melhor maneira de introduzir o tema da homossexualidade é fazê-lo do jeito mais natural e relaxado possível; desta maneira, evita-se alarmar os alunos com sinal de "controvérsia". Literatura/ cultura gay e lésbica não são uma "coisa" existente à parte de "nossa" sociedade que deve ser mencionada somente uma vez por ano nas margens do currículo para satisfazer uns poucos "progressistas". A questão gay e lésbica deve fazer parte do dia-a-dia nas salas de aulas e deve ser debatida e encarada como algo natural da vida sempre que o assunto for pertinente. (SANTOS, 1997, p. 186) 
Então, ao se colocarem, por exemplo, os livros $O$ gato que gostava de cenoura e $O$ menino que brincava de ser na pauta curricular de uma escola, o professor poderia levar em consideração, quando estivesse debatendo acerca da construção e da subjetividade dos personagens protagonistas das duas obras, que a diferença é constitutiva de suas identidades, além de problematizar a relação do eu com o outro no processo de alteridade, de modo a abordar a diferença em sua amplitude e de modo contextualizado social, cultural e historicamente.

É nesse sentido que acreditamos que a representação de identidades de gênero e de sexualidades fortalece a diversidade sexual. E a educação tem papel crucial na sua execução, pois éatravés dela, do seu podertransformacional, que podemos enxergar um caminho menos auspicioso ao romper com uma cultura maléfica, nociva e danosa, que serve para propagar o preconceito. Acreditamos, pelos motivos expostos ao longo de nosso texto, que somente através de uma educação ética e estética, que valorize o essencial do ser humano, baseada na igualdade, nos valores éticos e na cidadania, é que podemos conseguir, aos poucos, mudar a mentalidade de uma nação.

Mas, antes de tudo, é necessária uma valorização dos sujeitos marginalizados enquanto seres humanos - vistos 
e compreendidos na maioria das vezes apenas como objetos ou abjetos de nossa sociedade. Portanto, aqueles conservadores que não aceitam as diferenças do outro em sua multiplicidade deveriam, pelo menos, tentar compreender e aceitar esse "outro" na sua condição humana, considerando-se o princípio de igualdade perante a lei e a sociedade, de modo geral.

\section{REFERÊNCIAS}

ALVES, Rubens. O gato que gostava de cenouras. São Paulo: Loyola, 2009. BUTLER, Judith. Problemas de gênero: feminismo e subversão da identidade. Rio de Janeiro: Civilização Brasileira, 2008.

. Corpos que pesam: sobre os limites discursivos do "sexo". In: LOURO, Guacira Lopes (Org.). O corpo educado: pedagogias da sexualidade. Belo Horizonte: Autêntica, 2010. p. 151-172.

ERIBON, Didier. Reflexões sobre a questão gay. Rio de Janeiro: Companhia de Freud, 2008.

FOUCAUT, Michel. Disciplina. In: .Vigiar e punir: história da violência nas prisões. Petrópolis: Vozes, 2009. p. 130-214.

. História da sexualidade I: a vontade de saber. Rio de Janeiro:

Edições Graal, 2010.

LOURO, Guacira Lopes. Gênero, sexualidade e poder. In: (Org.). Gênero, sexualidade e educação: uma perspectiva pós-estruturalista. Petrópolis: Vozes, 1997, p. 37-56.

. Um corpo estranho. Ensaios sobre sexualidade e teoria queer. Belo Horizonte: Autêntica, 2008.

. Currículo, gênero e sexualidade. O "normal", o "diferente" e o

"excêntrico". In: LOURO, Guacira Lopes; FELIPE, Jane; GOELLNER, Silvana Viladre (Orgs.). Corpo, gênero e sexualidade. Um debate contemporâneo 
na educação. Petrópolis: Vozes, 2010a, p. 41-52.

Pedagogias da sexualidade. In: (Org.). O corpo educado: pedagogias da sexualidade. Belo Horizonte: Autêntica, 2010b, p. 7-34. MARTINS, Georgina da Costa. O menino que brincava de ser. São Paulo: DCL, 2000.

PAULINO, Graça. Livros, críticos, leitores: trânsitos de uma ética. In: PAIVA, Aparecida; MARTINS, Aracy; PAULINO, Graça; VERSIANI, Zélia (Orgs.). Literatura e letramento: espaços, suportes e interfaces - $O$ jogo do livro. Belo Horizonte: Autêntica/CEALE/UFMG, 2005 p. 13-20.

SHOHAT, Ella; STAM, Robert. Estereótipo, realismo eluta por representação. In: Crítica da imagem eurocêntrica: multiculturalismo e representação. São Paulo: Cosac Naify, 2006. p. 261-312.

SANTOS, Rick. Subvertendo o cânone: 'literatura gay e lésbica no currículo. In: Gragoatá. Niterói, n. 2, p. 181-189, 1 sem. 1997.

SANTOMÉ, Jurjo Torres. As culturas negadas e silenciadas no currículo. In: SILVA, Tomaz Tadeu da (Org.). Alienígenas na sala de aula: uma introdução aos estudos culturais em educação. Petrópolis: Vozes, 2009. p. 159-177. SEDGWICK, Eve Kosofsky. Epistemologia do armário. Coimbra: Angelus Novus: 2003.

SILVA, Tomaz Tadeu da. A produção social da identidade e da diferença. In: (Org.). Identidade e diferença. A perspectiva dos estudos culturais. Petrópolis: Vozes, 2007. p. 73-102. . Currículo e identidade social: territórios contestados. In:

(Org.). Alienígenas na sala de aula: uma introdução aos estudos culturais em educação. Petrópolis: Vozes, 2009. p. 190-207.

STEINER, George. Alfabetização humanista. In: Linguagem e silêncio: ensaios sobre a crise da palavra. São Paulo: Companhia das Letras, 1988. p. 21-29.

TURCHI, Maria Zaira. Uma aposta na esperança: ética e valores na constituição do sujeito. In: CECCANTINI, João Luís; PEREIRA, Rony Farto (Org.). Narrativas juvenis: outros modos de ler. São Paulo: Ed. UNESP; Assis: ANEP, 2008. p. 211-233. 
WOODWARD, Kathryn. Identidade e diferença: uma introdução teórica e conceitual. In: SILVA, Tomaz Tadeu da (Org.). Identidade e diferença. A perspectiva dos estudos culturais. Petrópolis: Vozes, 2007. p. 7-72.

Flávio Pereira Camargo é Pós-doutor em Estudos Literários pela UFMG. Doutor em Literatura pela UnB. Doutor e Mestre em Letras e Linguística (Estudos Literários) pela UFG. É líder do Grupo de Pesquisa "Estudos sobre a narrativa brasileira contemporânea" cadastrado no CNPq. Atualmente, é coordenador do Programa de Pós-Graduação em Letras: Ensino de Língua e Literatura, da Universidade Federal do Tocantins, em Araguaína.

Aurílio Soares da Silva é bolsista de Iniciação Científica do CNPq, desenvolvendo o projeto de pesquisa intitulado "Práticas discursivas de subjetivação na literatura infantil brasileira contemporânea", sob orientação do Prof. Dr. Flávio Camargo. É discente do Curso de Letras da UFT//Campus Universitário de Araguaína. 